\title{
Heterogeneously catalyzed conversion of nordic pulp to levulinic and formic acids
}

\author{
Johan Ahlkvist ${ }^{1}$ Johan Wärnå ${ }^{1,2}$ - Tapio Salmi ${ }^{2}$. \\ Jyri-Pekka Mikkola ${ }^{1,2}$
}

Received: 27 June 2016/Accepted: 11 August 2016/Published online: 19 August 2016

(C) The Author(s) 2016. This article is published with open access at Springerlink.com

\begin{abstract}
Herein, one-pot conversion of cellulose to platform chemicals, formic and levulinic acids was demonstrated. The catalyst selected was an affordable, acidic ion-exchange resin, Amberlyst 70, whereas the cellulose used was sulfite cellulose delivered by a Swedish pulp mill. Furthermore, in an attempt to better understand the complex hydrolysis network of the polysaccharide, kinetic experiments were carried out to pinpoint the optimal reaction conditions with an initial substrate concentration of $0.7-6.0 \mathrm{wt} \%$ and a temperature range of $180-200{ }^{\circ} \mathrm{C}$. Higher temperatures could not be used due to the limitations in the thermal stability of the catalyst. Overall, maximum theoretical yields of 59 and $68 \mathrm{~mol} \%$ were obtained for formic and levulinic acid, respectively. The parameters allowing for the best performance were reaction temperature of $180{ }^{\circ} \mathrm{C}$ and initial cellulose concentration of $0.7 \mathrm{wt} \%$. After studying the behavior of the system, a simplified reaction network in line with a mechanistic approach was developed and found to follow first order reaction kinetics. A satisfactory fit of the model to the experimental data was achieved (97.8\% degree of explanation). The catalyst chosen exhibited good mechanical strength under the experimental conditions and thus, a route providing green platform chemicals from soft wood pulp from coniferous trees (mixture of Scots Pine and Norway Spruce) was demonstrated.
\end{abstract}

Keywords Heterogeneous acid catalysis - Amberlyst 70 - Levulinic and formic acids

Jyri-Pekka Mikkola

jyri-pekka.mikkola@umu.se; jpmikkol@abo.fi

1 Technical Chemistry, Department of Chemistry, Chemical-Biochemical Centre, Umeå University, 90187 Umeå, Sweden

2 Laboratory of Industrial Chemistry and Reaction Engineering, Process Chemistry Centre, Åbo Akademi University, 20500 Turku, Finland 


\section{Introduction}

Lignocellulosic biomass such as wood is an excellent raw material for converting renewables into fuel components and chemicals, since the utilization of this kind of biomass does not compete with food or feed production. Chemical products produced from food-crops (e.g. corn) are questionable in a world where there is a lack of adequate nourishment for all its inhabitants. In fact, sugar crops like e.g. sugarcane is often grown for non-food purposes (primarily transportation fuel blends) on farmland that competes with human related food production. After the initial boom of first generation biochemicals and fuels made from edible biomass, an ever increasing number of the so-called second generation biofuels produced from non-edible biomass (e.g. agricultural residues, lignocellulosics and other waste materials) have been introduced. The development of new processes for woody biomass or other lignocellulosic materials has attracted increasing attention for some time now. In fact, commercial operations and pilot units are either integrated as biorefineries combined with adjacent pulp and paper mills (utilizing e.g. black liquor and other secondary streams as sources of new products) or built as standalone processing units. In order to combine and re-invent the material streams of the old industry together with other processes and practices of chemical industry, a lot of new R\&D efforts are required thus utilizing the existing and new technology solutions to produce a range of fossil-free alternatives of future.

In this paper, sulfite cellulose from a Swedish pulp mill was used as a raw material upon synthesis of green levulinic and formic acids. Today's standard pulping technology is the alkaline sulfate process, although the older, acidic sulfite process has a number of advantages over the currently dominant industrial approaches. In particular, the sulfite process is better adopted in the production of high-purity pulp essentially free of residual lignin and hemicellulose.

Furthermore, a solid acid, macro-porous, cationic ion-exchange resin, Amberlyst 70 was used as the hydrolysis catalyst. Since the catalyst particles most often used in industrial processes related to conversion of molecules such as carbohydrates and their polymers are relatively small (slurry reactors), one could easily consider that any such system operates in fact in the kinetic regime. Nevertheless, as an example, our earlier simulation results obtained for sugar hydrogenations evidently suggest that this is not necessarily the case [1]. Carbohydrates and their polymers are large, organic molecules with molecular diffusion coefficients in the magnitude of order of $4.0 \times 10^{-9} \mathrm{~m}^{2} \mathrm{~s}^{-1}$. In addition, the porosity-to-tortuosity factor can become small $(\ll 0.5)$ and, therefore, the effective diffusion coefficient can be rendered small, resulting in internal diffusion resistances that can have an important role. Still, external diffusion resistances can often be of crucial importance due hampered contact of reactant(s) with the active sites of the catalyst due to less than perfect mixing (improper stirrer or reactor vessel design or non-baffled reactor). This, in turn, can result in more prominent formation of by-products. Understandably, all these factors are even more pronounced when considering large, industrial-size cellulose cookers which easily accommodate tens of tons of material. 
Several kinetic studies using a various range of cellulosic materials can be found in the literature. Saeman [2] was one of the pioneers when he in 1945 presented a modelling study based on hydrolysis reaction of Douglas fir into glucose performed in a batch mode. Also, several later studies are based on Saemans model. In papers by Fagan et al. [3], Thompson and Grethlein [4], and Franzidis et al. [5] a plug-flow reactor was used to study the kinetics of the hydrolysis reaction of Kraft paper slurries, Solka Floc as well as filter paper. Also, Malester and co-workers [6, 7] were using Saemans model when the kinetics of dilute hydrolysis of cellulose originating from municipal solid wastes was investigated in a batch reactor. Nevertheless, only a few kinetic reports [8-10] are available for the acid-catalyzed hydrolysis of cellulose to levulinic acid before Girisuta et al. [11] who presented a more detailed reaction mechanism of levulinic acid (LA) formation from cellulose through glucose and 5-hydroxymethylfurfural (HMF), including the humin formation reactions. Jing and Lu [12] also published a model describing LA production based on a similar reaction mechanism performed in a batch autoclave using glucose as the reactant. Further, Shen and Wyman [13] presented a sophisticated model describing LA production in tubular batch reactors from microcrystalline cellulose and their model accounted for the major compounds as well as the side-reactions leading to by-products.

Hereupon we describe an experimental and modelling study of the acid-catalyzed hydrolysis of soft wood dissolving pulp into levulinic acids through glucose and $\mathrm{HMF}$ as well as xylose, furfural and formic acid from the transformation of xylans in the pulp.

\section{Materials and methods}

All the commercially acquired reagents and chemicals used were of analytical grade and used without further purifications or other treatment procedures. D-glucose (VWR International, >99 \%), 5-hydroxymethylfurfural (Aldrich, $99 \%$ ), levulinic acid (Janssen Chimica, 98+ \%) and formic acid (Sigma-Aldrich, 98-100 \%) were used to facilitate the calibration curves needed to follow the reaction kinetics. HPLC grade sulfuric acid (Fluka, $50 \%$ ) was used for eluent preparation. Deionized water (MilliQ) was used to prepare all the solutions. The polymeric catalyst, Amberlyst 70, was supplied by the Rohm and Haas Company (as a gift for which the authors are grateful). Amberlyst 70 is a macro-porous, polymeric, cationic ion-exchange resin material applicable in high-temperature applications and is designed to be used in various processes like olefin hydration, esterification and aromatic alkylation. In the aforementioned applications, Amberlyst 70 offers good performance advantages over conventional resins due to its high thermal stability (up to $190{ }^{\circ} \mathrm{C}$ ), catalytic activity and good mechanical strength. Importantly, rather low sulfonate leaching has also been confirmed. The appearance of the catalyst is dark brown, spherical particles with an effective particle size of around $0.50 \mathrm{~mm}$. The average pore diameter was measured and corresponded to $220 \AA$ (22 nm). The nitrogen physisorption (in accordance to the B.E.T. method) confirmed a specific surface area in the range of $36 \mathrm{~m}^{2} \mathrm{~g}^{-1}$ [14-17]. 


\section{Cellulose pulp utilized}

In this study, the focus was in the catalytic transformation of bleached, softwood sulfite dissolving pulp (from a mixture of Norway spruce and Scots pine) from the Aditya Birla Domsjö pulp mill in Sweden. The softwood pulp obtained as a gift from the Domsjö mill has a typical degree of polymerization (DP) ranging from 650 to 1250 with an average of 950 . Also, the glucose concentration for the Domsjö pulp was $91.2 \mathrm{wt} \%(89.6-91.4 \%)$ and the total hemicelluloses content (sum of xylose and mannose) $4.18 \mathrm{wt} \%$ (3.24-5.63\%), respectively [18]. The pulp was utilized without any prior mechanical or chemical treatment. Deionized water was used for preparation of all reaction solutions.

\section{Chemical analysis of the product mixture}

The composition of the samples was analyzed off-line with high-performance liquid chromatography (HPLC, Agilent Technologies 1200 Series) equipped with a refractive index (RI)-detector, a degasser, a double-channel binary pump and an auto sampler. $5 \mathrm{mM}$ sulfuric acid was utilized as the mobile phase with a flow rate of $0.5 \mathrm{~cm}^{3} \mathrm{~min}^{-1}$ and temperature of $60{ }^{\circ} \mathrm{C}$. The analysis for a sample was completed within $1 \mathrm{~h}$. The samples were injected into the HPLC's directly after the sample was taken without any pre-treatment other than filtering $(2 \mu \mathrm{m})$ to prevent column damage. The analysis for a sample was completed within $1 \mathrm{~h}$. The concentrations of each compound in the liquid-phase mixture were determined using calibration curves obtained by analyzing standard solutions with known concentrations.

\section{Study of reaction kinetics}

All kinetic experiments were carried out in two $300 \mathrm{ml}$ laboratory scale, three-phase stainless-steel/circonium autoclaves (Parr Inc, USA), capable of operating at high pressures and temperatures. The temperature was measured with a thermocouple and automatically adjusted with an inbuilt temperature regulator (Parr 4848 Reactor Controller). The autoclave was equipped with a gas inlet/sampling outlet fitted with a $7 \mu \mathrm{m}$ metal sinter frit designed to prevent the catalyst particles as well as pulp pieces to leave the reaction vessel upon sampling of the liquid phase. The hydrolytic degradation of wood pulp took place in the presence of catalysts in an aqueous media and high stirring rates $(1000 \mathrm{rpm})$ were applied in order to eliminate any external mass transfer limitations. The reaction parameters studied, such as the reaction time, temperature, pressure as well as the nature of the catalyst was of crucial importance in terms of optimal conversion of the biopolymers to platform chemicals. Each and every experiment was commenced by charging the reaction vessel with a slurry containing 1-9 g of pulp dispersed in 141-149 $\mathrm{ml}$ of deionized water along with 1-9 g of catalyst. Before heating the reaction mixture to the intended temperature $\left(180-200{ }^{\circ} \mathrm{C}\right)$, the system was degassed $(<0.01 \mathrm{~atm})$ with a high power vacuum pump to remove any residual air in the solution. After reaching the preset temperature, the agitation was engaged, carbon dioxide gas atmosphere 
was applied at set pressure (50.0 bar excluding vapor pressure from water) and this was considered as the initial start of the reaction. Throughout the experimental run, samples were taken at suitable intervals and the sampling line was flushed with small volumes of the reaction solution in between the samples to avoid any contamination between consecutive samples. For the sake of precaution, the samples were once more filtered and the composition was determined by means of high-performance liquid chromatography (HPLC).

\section{Modelling software and techniques}

For the modeling of the reaction kinetics, the software Modest ${ }^{\circledR}$ was used [19]. The software solves the reactor model equations (system of ordinary differential equations) with the backward difference method and optimizes the parameter values using a hybrid method involving Simflex and Levenberg-Marquardt methods.

\section{Results}

\section{Reaction products}

The simplified reaction network for the acid-catalyzed hydrolysis of wood pulp to levulinic acid is schematically given in Fig. 1 . The complete reaction network involves a sequence of hydrolysis hydration-dehydration reactions. At first, the biopolymer chains (cellulose and hemicelluloses present in the pulp) are broken down into low molecular weight, oligomeric species-also followed by hydrolytic degradation reactions giving rise to by-products. Two reaction pathways are involved: the degradation of cellulose leads to the formation of glucose, while the degradation of hemicelluloses generates xylose. The glucose formed is further transformed to 5-hydroxymethylfurfural (HMF) which, in turn, is further converted in a consecutive hydration-dehydration reaction sequence to levulinic acid (LA) and formic acid (FA). Fructose is also a known intermediate in acid catalyzed hydrolysis of glucose, but could not be detected in our study probably because the dehydration of fructose to HMF is much faster than dehydration of glucose. The formation of xylose confirms the presence of hemicelluloses xylanes in the pulp. The xylose fraction yields furfural and is finally decomposed to formic acid. Furthermore, formation of humins (or tar-like species) directly from cellulose and sugars readily occurs when the carbohydrate fractions are getting in contact with the hot walls of the reaction vessel. Throughout all kinetic experiments, black insoluble substances known as humins were formed on the reactor walls and the amount was visibly increased with reaction time. These are well known products of side-reactions of the acid-catalyzed decomposition of pulp (cellulose). Girisuta et al. [20] confirmed by elemental analysis that the solids are a mixture consisting mainly of humins (typical composition: $\mathrm{C}, 63.1 ; \mathrm{H}, 4.2)$ and some unreacted cellulose $(\mathrm{C}, 42.2 ; \mathrm{H}, 6.1)$. In addition to the anticipated products, Girisuta et al. [21] also detected small amounts of glucose-reversion products (e.g., levoglucosan, isomaltose and gentiobiose). The formation of the reversion products was also observed in this study, but the 


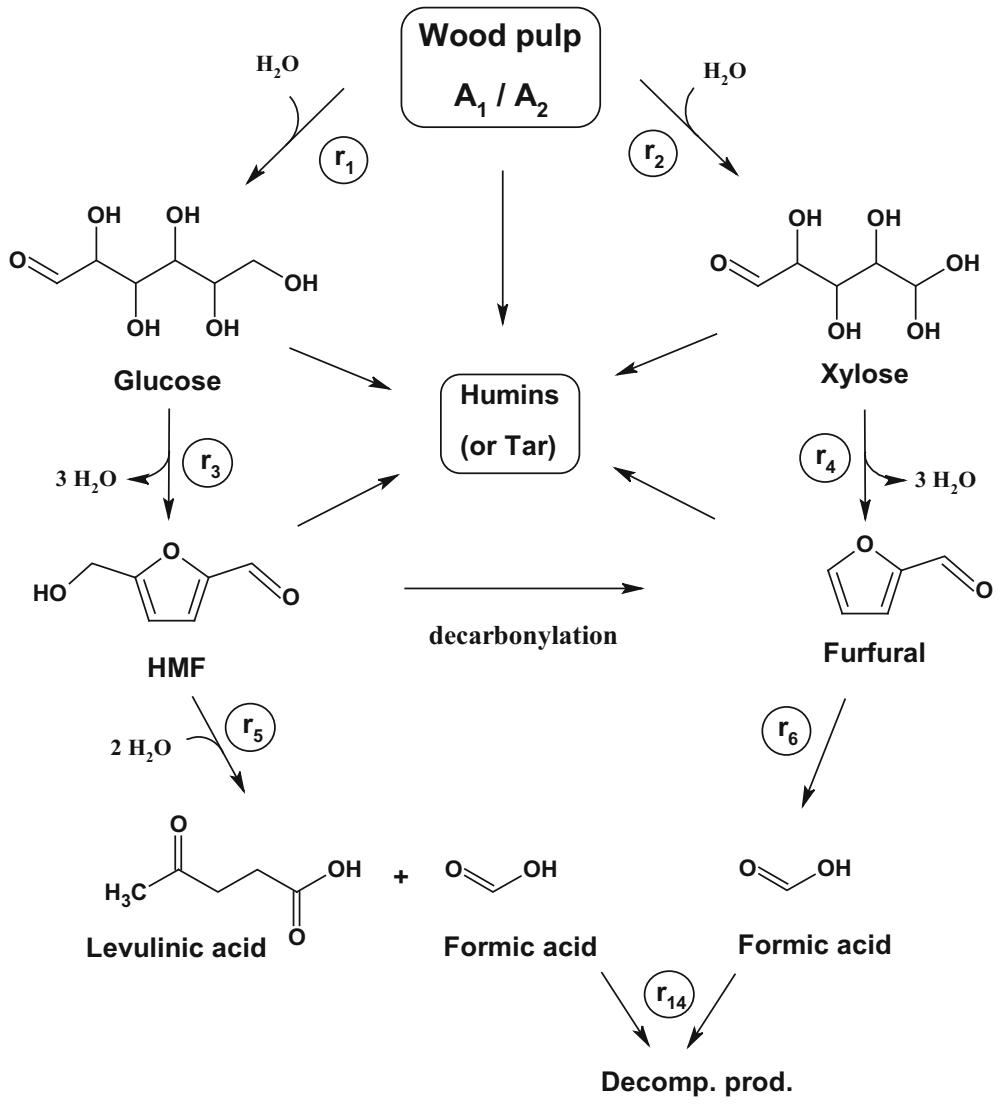

Fig. 1 The reaction network upon production of the platform chemicals levulinic and formic acids from cellulose as well as the reactions used in the mathematical model

maximum amount of these products was very low and not accurately quantified. Other possible by-products of the acid-catalyzed hydrolysis of cellulose are gasphase components from thermal degradation reactions of reactants and/or products. To gain insights into the extent of these reactions, GC and GC-MS studies were carried out to analyze the gas phase composition during an experiment performed at $180{ }^{\circ} \mathrm{C}$ without any gas addition. $\mathrm{CO}, \mathrm{CO}_{2}$ and $\mathrm{H}_{2}$ are typically detected. However, the amounts observed were below $0.1 \mathrm{wt} \%$ of the cellulose intake. This implies that the formation of gas-phase compounds is only a minor reaction pathway under the investigated reaction conditions, particularly at lower temperatures. However, we could not quantify the presence of any formed carbon dioxide since it was used to pressurize the reactor system during our experiments. Plausibly, the amount of $\mathrm{CO}$ and $\mathrm{CO}_{2}$ should increase with increasing reaction temperatures, although no conclusive evidence could be obtained. Formic acid decomposes primarily to $\mathrm{CO}$ and $\mathrm{H}_{2} \mathrm{O}$ in the gas phase (dehydration) but to $\mathrm{CO}_{2}$ and $\mathrm{H}_{2}$ (decarboxylation) in the aqueous phase [22]. The occurrence of these phenomena was indicated by a small 
increase in the total pressure of the reaction vessel, especially at higher reaction temperatures. Fig. 2 illustrates the maximum levulinic acid yields obtained upon kinetic experiments conducted at different acid and substrate concentrations. Theoretically, a higher liquid-to-solid ratio should result in a higher yield of levulinic acid. However, it was further observed that higher substrate loadings had an adverse effect in terms of the final levulinic acid yields detected in the reaction mixture. These observations are in line with other studies on the acid-catalyzed decompositions of HMF and glucose, whereupon low substrate concentrations favored high LA yields. Generally, lower concentration of cellulose resulted in higher yields of levulinic acid. For each levulinic acid molecule generated, two molecules of water are needed, otherwise 5-hydroxymethylfurfural (HMF) may be converted into humins [21]. As also depicted by Fig. 2, evidently there exists an optimal catalyst loading. Consequently, the addition of excess catalyst has little or even negative effect on the LA yield. In fact, Yan et al. [23] also observed that low concentration of hydrochloride acid resulted in too low concentration of $\mathrm{H}^{+}$ions thus being unable to facilitate cellulose hydrolysis and, consequently, a low reaction rate was observed. Using low acid concentrations is problematic, because the lignin and other impurities present in the biomass consumes a fraction of the acid during the reaction. In our case, a load of $9 \mathrm{~g}$ substrate and $1 \mathrm{~g}$ catalyst resulted in only $5.9 \mathrm{~mol} \%$ yield of levulinic acid, at a reaction temperature of $190{ }^{\circ} \mathrm{C}$.

\section{Modelling of the reaction system}

In our recent paper [24], a prototype kinetic model for the acid-catalyzed hydrolysis of dissolving pulp was introduced; Nevertheless, although the model introduced here was validated during similar reaction conditions, the new model is more sophisticated and is also based on additional kinetic experiments. Upon modelling of the reaction kinetics, Modest ${ }^{\circledR}$ was used [19]. The software uses the backward difference method to solve the reactor mass balances (a system of ordinary differential equations, ODEs) and a hybrid method involving Simflex and Levenberg-Marquardt methods for the estimation of the kinetic parameters (rate constants and activation energies) defined in the kinetic model. Consequently, the rate equations for the proposed elementary reaction kinetic model and batch reactor
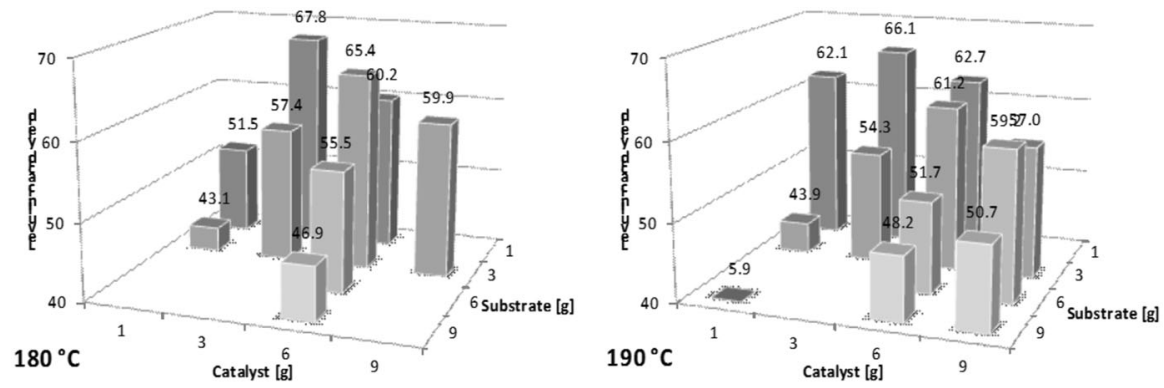

Fig. 2 Maximum levulinic acid yields formed at 180 and $190{ }^{\circ} \mathrm{C}$ at different acid and substrate concentrations 
model were implemented in the software which also provides the graphical interface.

For the parameter estimation the following objective function was minimized.

$$
Q=\sum_{t} \sum_{i}\left(c_{i, t, \exp }-c_{i, t, \text { model }}\right)^{2} w_{i, t}
$$

Here $c_{i, t, \text { exp }}$ and $c_{i, t, \text { model }}$ are the experimentally recorded concentrations and the concentrations predicted by the model, respectively. The weight factors, $w_{i}$, were at this time set equal to unity (1) for all experimental data.

The reaction system was described with the following reactions:

$$
\begin{gathered}
A_{1} \stackrel{r_{1}}{\rightarrow} \text { Glucose } \stackrel{r_{3}}{\rightarrow} \text { HMF } \stackrel{r_{5}}{\rightarrow} \text { Levulinicacid }+ \text { Formicacid } \\
A_{2} \stackrel{r_{2}}{\rightarrow} \text { Xylose } \stackrel{r_{4}}{\rightarrow} \text { Furfural } \stackrel{r_{6}}{\rightarrow} \text { Formicacid } \\
\text { Formicacid } \stackrel{r_{14}}{\rightarrow} \text { Decomposedproducts }
\end{gathered}
$$

In the initial approach, only the experimental runs at higher temperature range, i.e. $180-200{ }^{\circ} \mathrm{C}$, were concerned since the reaction proceeds extremely sluggishly at lower temperatures and batch experiments lasting for several days had to be carried out. Nevertheless, some preliminary modeling revealed that a first order reaction kinetics model is able to describe the reactions in a reasonable and simple way. Thus, the reaction rates were determined as follows:

$$
r_{j}=k_{j} c_{i}
$$

Here $r_{j}$ denotes the individual reaction rate for the reaction $j, k_{j}$ denotes the reaction rate constant and $c_{i}$ the concentration of component $i$. On the other hand, the temperature influence on the reaction rate was taken into account with the Arrhenius equation:

$$
k_{j}=k_{0 j} e^{-\frac{E_{A j}}{R}\left(\frac{1}{T}-\frac{1}{T_{\text {mean }}}\right)}
$$

Thus, $k_{j}$ denotes the reaction rate constant, $k_{o j}$ the frequency factor, $R$ is the ideal gas constant, $\mathrm{T}$ is the temperature and $E_{A j}$ the activation energy.

The modeling approach chosen verified that the experimental results obtained at $180-200{ }^{\circ} \mathrm{C}$, in the heterogeneously catalyzed reaction, displayed prominent Arrhenius-type temperature dependence demonstrated for the reaction products identified.

For the reactor, the ideal batch reactor model was used.

$$
\frac{d c_{i}}{d t}=r_{i} m_{c a t}
$$

Here $c_{i}$ denotes the concentration of component $i, r_{i}$ the generation rate for component $i$ and $m_{\text {cat }}$ the catalyst amount. 
The parameters (frequency factors $k_{0 j}$, activation energies $E_{A j}$ ) were estimated using the parameter estimation software. Estimation of the reaction kinetics parameters were split into two parts, whereupon first only parameters for the reactions $r_{2}, r_{4}$ and $r_{6}$ were estimated, after which the parameters for $r_{2}, r_{4}$ and $r_{6}$ were fixed and the rest of the parameters were estimated. Initially, an estimation of all parameters simultaneously was tried but it did not give good results for the reactions $r_{2}$ and $r_{4}$ (formation of xylose and furfural), mainly due to large differences in the concentration levels of the compounds present thus leading to unstable behavior of the solver. The values of the estimated parameters are enlisted in Table 1.

The most common measure for the goodness of fit is the degree of explanation, the $R^{2}$-value. The idea is to compare the residuals given by the model to the residuals of the simplest model one may think of, the average value of all the data points. The $R^{2}$ value is given by the expression:

$$
R^{2}=100 \frac{\left(y_{\text {model }}-y_{\text {exp eriment }}\right)^{2}}{\left(y_{\text {model }}-\bar{y}_{\text {exp eriment }}\right)^{2}}
$$

Here the y values denotes the estimated versus measured values of the respective parameters. For the parameter estimation, the degree of explanation of $97.8 \%$ was obtained.

The distribution and sensitivity of the parameters were controlled with the Markov Chain Monte Carlo method (MCMC), see Fig. 3. These figures also show low correlations between parameters and confirm well identified optimal values.

Figs. 4, 5, and 6 show that the model can predict the behavior of the reaction at different conditions as displayed in the parity plot in Fig. 7.

Table 1 Numerical values for the estimated parameters (degree of explanation $97.8 \%$ )

$\mathrm{T}_{\text {mean }}=185^{\circ} \mathrm{C}$, frequency

\begin{tabular}{llll}
\cline { 2 - 3 } & $k_{01}$ & 2.7 & 1.5 \\
$k_{02}$ & $k_{03}$ & 15.3 & 11.8 \\
& $k_{04}$ & 18.9 & 4.3 \\
& $k_{05}$ & 30.8 & 8.4 \\
& $k_{06}$ & 291 & 130 \\
& $k_{014}$ & 40.7 & 14.2 \\
& $E_{A 1}$ & 0.429 & 2.7 \\
$\mathrm{~T}_{\text {mean }}=185^{\circ} \mathrm{C}$, frequency & $E_{A 2}$ & 163 & 82.7 \\
factor $\left(k_{\mathrm{oj}}\right)$ in $\mathrm{h}^{-1}$ and activation & $E_{A 3}$ & 33.3 & 7.2 \\
energy $\left(E_{A j}\right)$ in $\mathrm{kJ} /$ mol & $E_{A 4}$ & 163 & 34.1 \\
& $E_{A 5}$ & 64.5 & 2705 \\
& & 8.83 & 203 \\
\end{tabular}



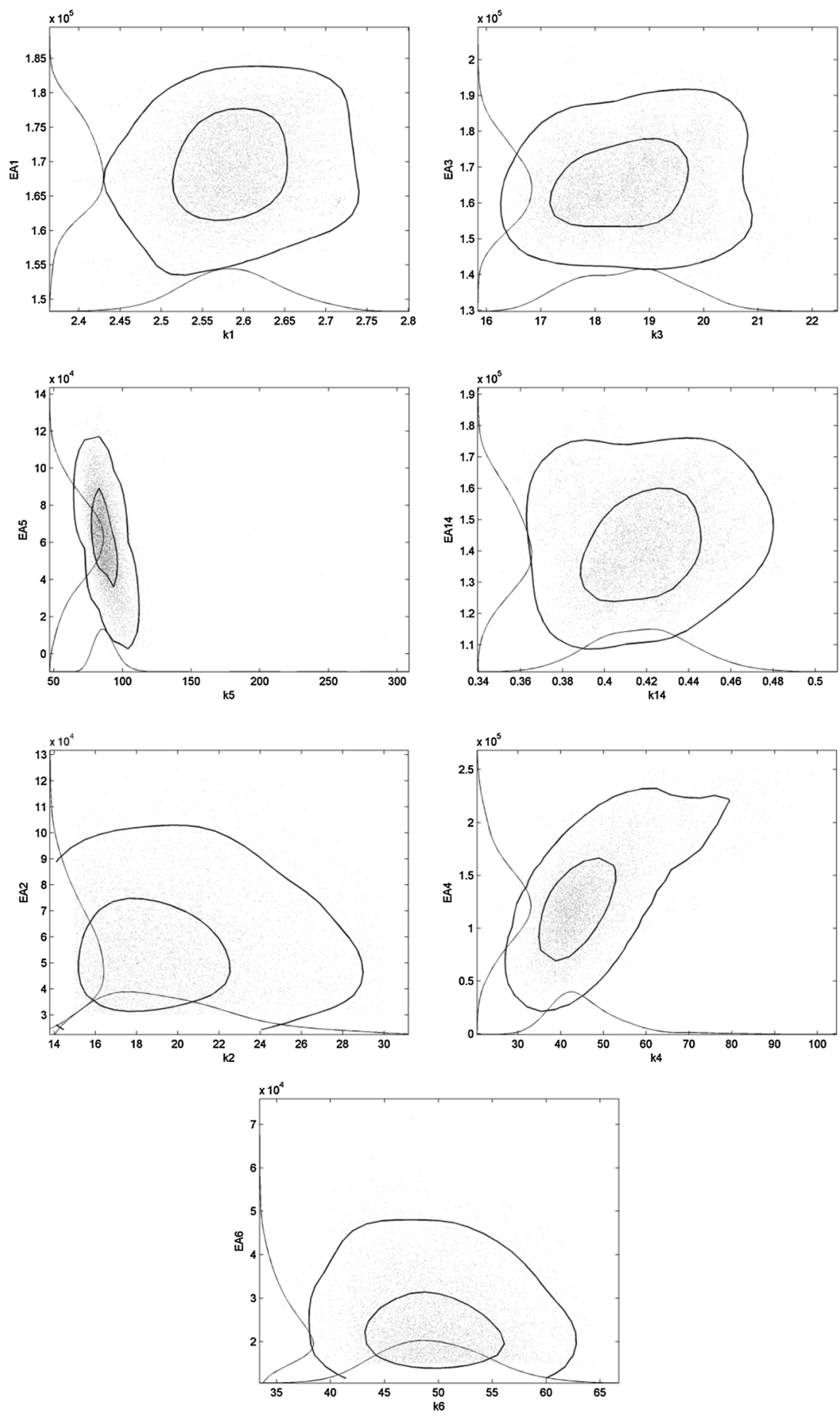

Fig. 3 Sensitivity analysis for the adjustable model parameters

\section{Springer}



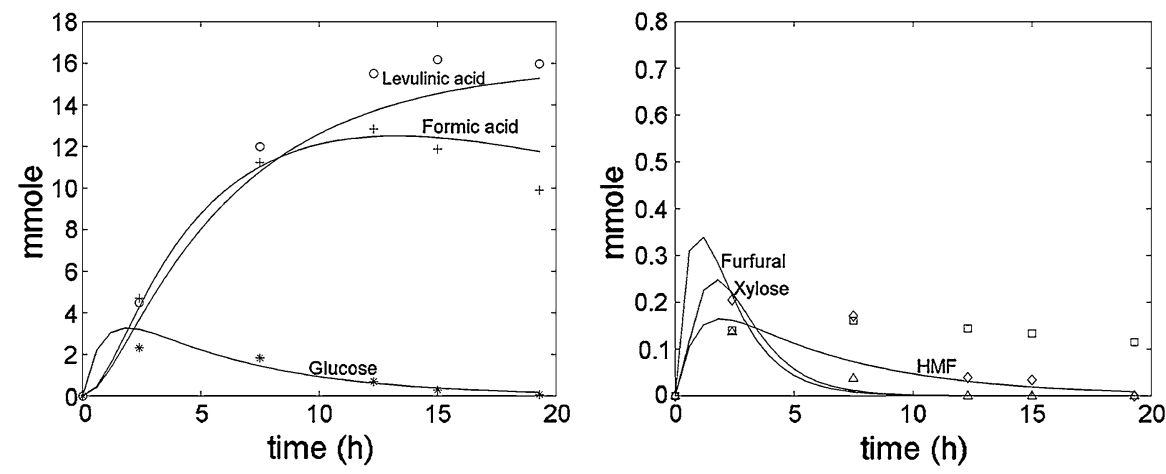

Fig. 4 Model fit to experimental data for one of the experiments performed at $190{ }^{\circ} \mathrm{C}$ with $6 \mathrm{~g}$ catalyst and substrate. Levulinic acid (open circle), formic acid (plus), glucose (asterisks), 5-HMF (open diamond), xylose (open triangle) and furfural (open square) versus time
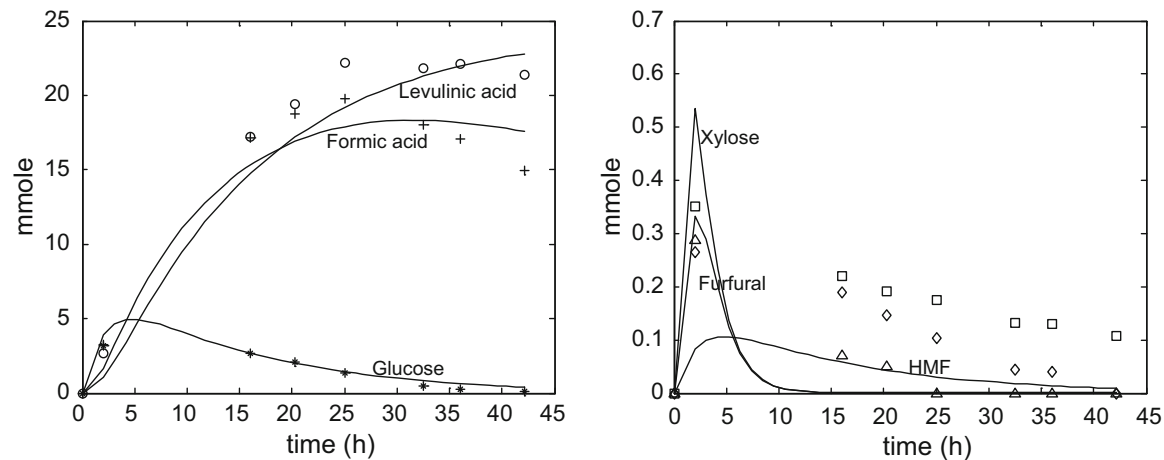

Fig. 5 Model fit to experimental data for one of the experiments performed at $180{ }^{\circ} \mathrm{C}$ with $6 \mathrm{~g}$ catalyst and $9 \mathrm{~g}$ substrate. Levulinic acid (open circle), formic acid (plus), glucose (asterisks), 5-HMF (open diamond), xylose (open triangle) and furfural (open square) versus time
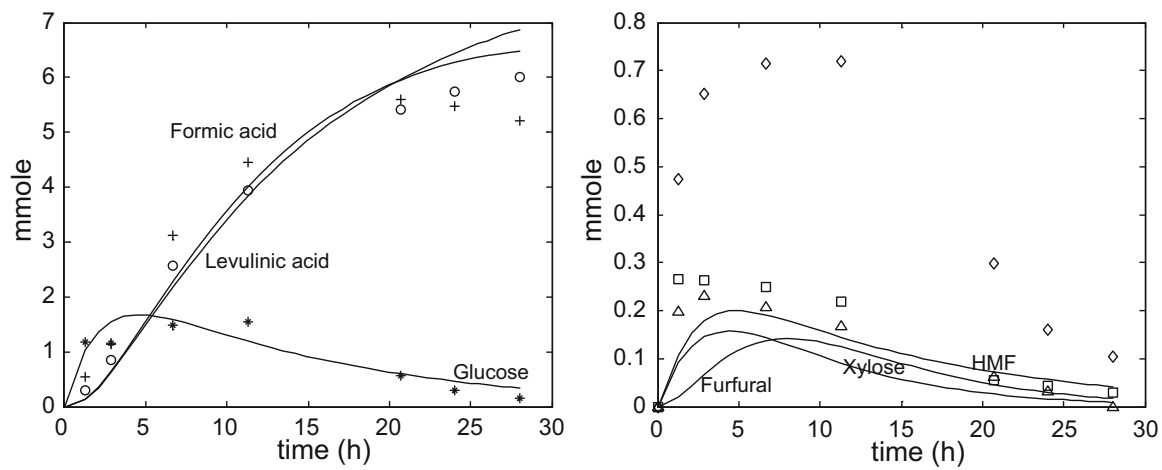

Fig. 6 Model fit to experimental data for one of the experiments performed at $200{ }^{\circ} \mathrm{C}$ with $1 \mathrm{~g}$ catalyst and $3 \mathrm{~g}$ substrate. Levulinic acid (open circle), formic acid (plus), glucose (asterisks), 5-HMF (open diamond), xylose (open triangle) and furfural (open square) versus time 


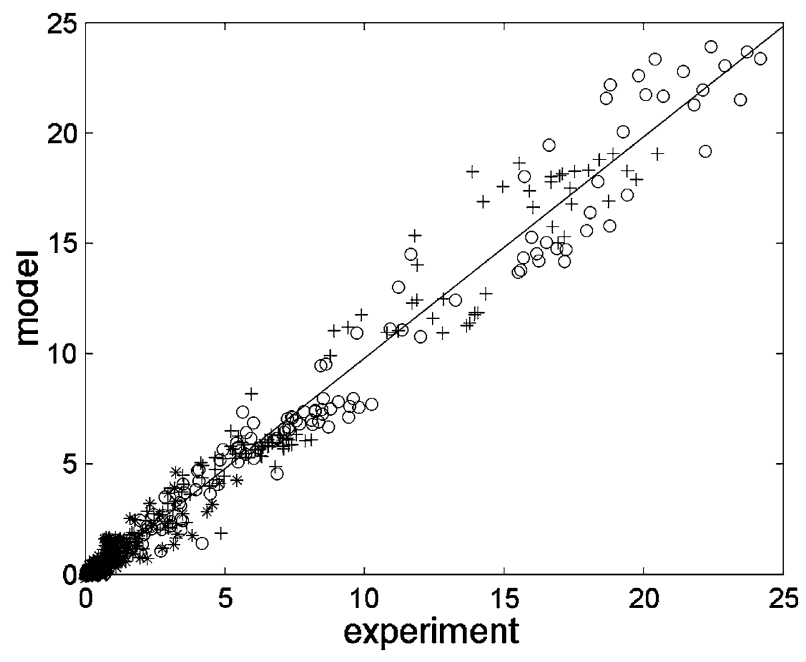

Fig. 7 Model fit to all experimental data [levulinic acid (open circle), formic acid (plus), and glucose (asterisks)]

\section{Conclusions}

Solid acid catalyzed degradation of bleached Nordic industrial dissolving pulp was investigated under mild batch wise reaction conditions to yield useful platform chemicals-levulinic and formic acids. The optimal reaction conditions were determined and a simple, first order kinetic approach was developed to describe the experimental data with satisfactorily accuracy. Sulfite-cellulose, being lean on pentose sugar containing hemicelluloses was revealed as a good raw material, thus resulting in 59 and $68 \mathrm{~mol} \%$ theoretical yields of levulinic versus formic acid, respectively, obtained at a reaction temperature of $180{ }^{\circ} \mathrm{C}$ and at a low initial cellulose concentration. It was also observed that excessively high reaction temperatures contribute to thermal degradation of the formed formic acid, since formic acid tends to degrade to carbon dioxide, carbon monoxide, hydrogen and water, which in turn led to lower overall yields of the desired products.

Acknowledgments Financial support from the Bio4Energy programme and Kempe Foundations are gratefully acknowledged. Further, collaboration with the SP Processum Biorefinery Initiative AB is acknowledged. This work is also a part of activities at the Johan Gadolin Åbo Akademi Process Chemistry Centre as well as Wallenberg Wood Science Center.

Open Access This article is distributed under the terms of the Creative Commons Attribution 4.0 International License (http://creativecommons.org/licenses/by/4.0/), which permits unrestricted use, distribution, and reproduction in any medium, provided you give appropriate credit to the original author(s) and the source, provide a link to the Creative Commons license, and indicate if changes were made. 


\section{References}

1. Salmi T, Kuusisto J, Wärnå J, Mikkola J (2006) Chim Ind 88:90-96

2. Saeman JF (1945) Ind Eng Chem 37:43-52

3. Fagan RD, Grethlein HE, Converse AO, Porteous A (1971) Environ Sci Technol 5:545-547

4. Thompson DR, Grethlein HE (1979) Ind Eng Chem Prod Res Dev 18:166-169

5. Franzidis J-P, Porteous A, Anderson J (1982) Conserv Recycl 5:215-225

6. Green M, Kimchie S, Malester A, Rugg B, Shelef G (1988) Biol wastes 26:285-295

7. Malester IA, Green M, Shelef G (1992) Ind Eng Chem Res 31:1998-2003

8. Efremov AA, Pervyshina GG, Kuznetsov BN (1998) Chem Nat Compd 34:182-185

9. Fang Q, Hanna MA (2002) Bioresour Technol 81:187-192

10. T. Frost, E. Kurth, in, Tappi, 1951

11. Girisuta B, Janssen LPBM, Heeres HJ (2007) Ind Eng Chem Res 46:1696-1708

12. Jing Q, LÜ X (2008) Chin J Chem Eng 16:890-894

13. Shen J, Wyman CE (2012) AIChE J 58:236-246

14. Ahlkvist J, Ajaikumar S, Larsson W, Mikkola J-P (2013) Appl Catal A 454:21-29

15. Siril PF, Cross HE, Brown DR (2008) J Mol Catal A 279:63-68

16. Bringué R, Iborra M, Tejero J, Izquierdo JF, Cunill F, Fité C, Cruz VJ (2006) J Catal 244:33-42

17. Rohm and Haas Company, 2005, Product data sheet www.amberlyst.com/literature/a4/70.pdf Accessed 06 Apr 2013

18. Strunk P, Öman T, Gorzsás A, Hedenström M, Eliasson B (2011) Nord Pulp Pap Res J 26:398

19. Haario H (1994) Modest User's Guide. Profmath Oy, Helsinki

20. Girisuta B, Janssen LPBM, Heeres HJ (2006) Green Chem 8:701-709

21. Girisuta B, Janssen LPBM, Heeres HJ (2006) Chem Eng Res Des 84:339-349

22. Akiya N, Savage PE (1998) AIChE J 44:405-415

23. Yan L, Yang N, Pang H, Liao B (2008) CLEAN Soil Air Water 36:158-163

24. Ahlkvist J, Ajaikumar S, Larsson W, Wärnå J, Salmi T, Mikkola J-P (2013) Chem Eng 32:649-654 